\title{
Application of Remotely Sensed Indices to Monitor and Detect the Changes of Land Cover: A Case Study of Abis Area, West Delta, Egypt
}

\author{
M. Ismail, I. Morsy ${ }^{*}$ and H. Yehia* \\ Remote Sensing and Geographic Information System Unit and \\ *Soil Salinity and Alkalinity Research Department, Soil, Water \\ and Environment Research Institute (SWERI), Agricultural \\ Research Centre, Cairo, Egypt.
}

\begin{abstract}
D ERIODIC and precise change detection of Earth's surface features is extremely important for understanding relationships and interactions between human and natural phenomena in order to promote better decision making. Land cover changes are of high importance for investigating the processes and patterns of landscape changes over time and the impact of these changes on sustainable development. These changes can be identified by exploiting multitemporal remote sensing images. Abis is an agricultural area having about 40,000 fed. that have been reclaimed in 1960 in two phases, the first phase was estimated at about 32,000 fed. adjacent to El Behira Governorate, then 8,000 fed. in Alexandria Governorate has been reclaimed at the beginning of the twentieth century. Three satellite images have been used in this study, TM 1984, Landsat ETM+7 2005 and ETM+8 2013 to study the land cover changes and their impact on agricultural land in Abis area, West Nile Delta, Egypt. New remote sensing indices were used to study changes of land cover namely NDVI, MNDWI, SAVI, and IBI. The bare soil and urban areas decreased from 5613 fed. in 1984 to 3117 fed. in 2005 due to it's the date of the second phase of reclaimed area. The bare soil and urban area increased from 3117 fed in 2005 on the other hand to 8264 fed in 2013. This means that more than $20 \%$ of the study area transformed from agricultural land to bare soil and urban area at 8 years, this means that we have lost some of the good and productive agricultural land in the period between 2005 and 2013. It is likely that most of this agricultural land will disappear if the continued encroachment on agricultural land remains the same.
\end{abstract}

Keywords: Change detection, Urbanization, Land cover, GIS, NDVI, NDBI, SAVI, and IBI.

The visual interpretation was an effective way for extracting an urban settlement accurately. The Greater Cairo area has undergone a very severe land cover change as a result of urbanization which resulted from rapid population growth. A Considerable increase in urban settlements has taken place at the expense of the most fertile land in the study area. GIS provided valuable information on the nature of urban sprawl through integration of soil digital database and urban map that resulted from visual interpretation. The main 
causes of urbanization are the rapid population growth in addition to the economic growth. Urban sprawl is one of the dominant land degradation processes in the study area. This problem needs to be seriously studied, through multi-dimensional fields including socioeconomic, in order to preserve the precious and limited agricultural land and increase food production (Afifi $e t$ al., 2013). Due to complexity of range ecosystem it is too difficult to show all changes with one quantitative model. However suitable indices and ratios obtained from different vegetation communities in this study can provide accurate estimations from vegetation parameters. Criteria that make an imagebased vegetation index suitable for regional monitoring are strongly related to vegetation cover in the vegetation types of the district, and an ability to predict this cover within semi-arid regions. However, this suggests that NDVI and simple redinfrared indices are useful for general cover monitoring regardless of more localised soil and vegetation variation (Amiri and Tabatabaie, 2011). Many studies demonstrated that the built-up land class cannot be efficiently enhanced using an index constructed simply of original multi spectral bands because the class has a heterogeneous characteristic. The proposed IBI is distinguished from conventional indices by the first-time use of thematic indexderived bands to construct an index, rather than by using original image bands. The new image, composed of three thematic index bands, the Soil Adjustment Vegetation Index (SAVI), the Normalized Difference Built-up Index (NDBI) and the Modified Normalized Difference Water Index (MNDWI), can greatly reduce the data dimensionality and redundancy of the original multi-spectral image and substantially avoids the spectral confusion between land use classes. Consequently, the IBI can effectively suppress background noise while retaining built up land features in satellite imagery (Xu, 2008). With the development of urban utility and service facilities around the city centers, urban sprawl would mainly impact on natural resources, i.e., agricultural land, water bodies, forest and fringe ecology. The future scope of this work would look into generating the images of further sprawl under different scenarios to understand new threat to urban-agro ecosystem. This will judiciously demonstrate the application of geospatial technology in studying the dynamics of urban sprawl in Indian cities and elsewhere (Rahman et at., 2011).

The main objectives of this study are; 1) To delineate the land cover changes spatially and quantitatively in Abis area using new remotely sensed indices, 2) To examine the capabilities of integrating remote sensing and GIS in studying the spatial distribution and extent of the bare soil and urban areas on fertile land.

\section{Study area}

The study area, located between $31^{\circ} 00^{\prime}$ and $31^{\circ} 30^{\prime} \mathrm{N}$ and $29^{\circ} 30^{\prime}$ and $30^{\circ} 30^{\prime}$ E. It is bounded from the south and east by Kafr El Dawar District, from the north and west by Alexandria City. The study area is characterized by a specific location since it is considered between two main Egyptian governorates El Behira and Alexandria. The total area of the study area is estimated to be 40968.79 fed., where the cultivated area is representing $77.18 \%$ of its total coverage. The common activity in the study area is mostly agriculture, in Egypt. J. Soil Sci. 55, No. 3 (2015) 
addition to the existence of some industrial parks and fish farms. The climatic data of Abis area indicate that the total rainfalls does not exceed $29 \mathrm{~mm} / \mathrm{year}$ and the mean minimum and maximum annual temperatures are 14.3 and 25.6 ${ }^{\circ} \mathrm{C}$, respectively. The evaporation rates are coinciding with temperatures, where the maximum average reference evaporation is $5.8 \mathrm{~mm}$ in July, while the minimum average reference evaporation is $2.2 \mathrm{~mm}$ in January. According to the aridity index classes (Hulme and March, 1990), the study area is located under arid climatic conditions (Map 1).

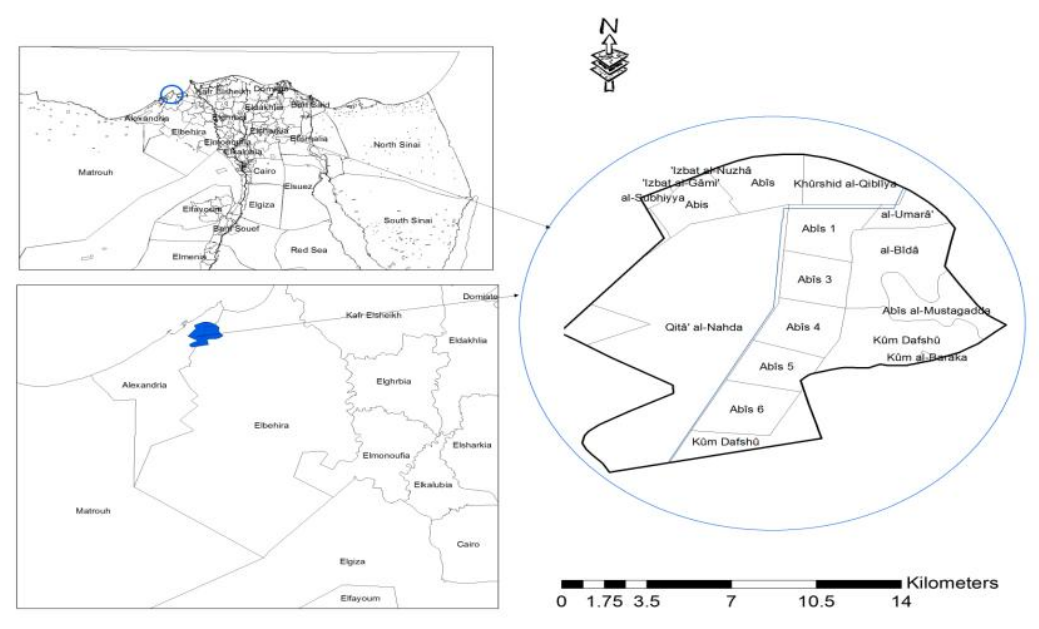

Map 1. General location of the study area.

\section{Soil mapping units}

The soil mapping units were extracted from the overlay of some layers of the main soil properties in the GIS procedure such as soil depth, soil salinity, total calcium carbonate and soil texture. Twelve soil units were established in the study area as shown in Map 2 (Yehia et al., 2014).

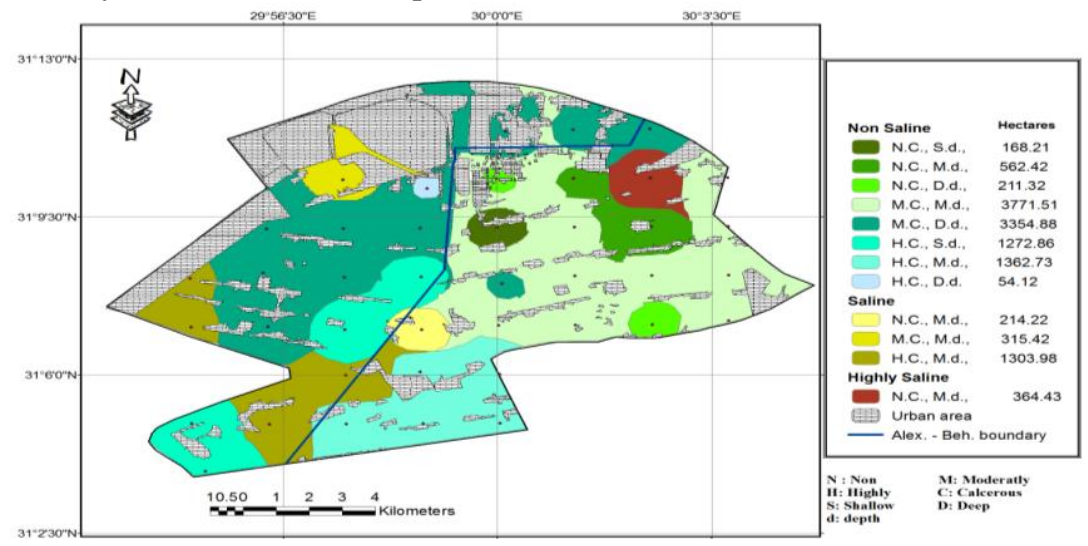

Map 2. Soil mapping units of the study area.

Egypt. J. Soil Sci. 55, No. 3 (2015) 
Land capability evaluation

The ALES Model provides prediction for general land use capability for a broad series of possible uses. According to the model prediction, most of the study area was classified as (C2aw, kh). This indicated a good capability with available water and hydraulic conductivity as limiting factor which covered about $31.31 \%$ of the total area mostly found in El Behira governorate. Other class (C2aw) indicated a good capability with available water as limiting factor which covered about $24.25 \%$ of the total area mostly focused in Alexandria Governorate. Map 3 shows the distribution of capability classes in the study area (Yehia et al., 2014).

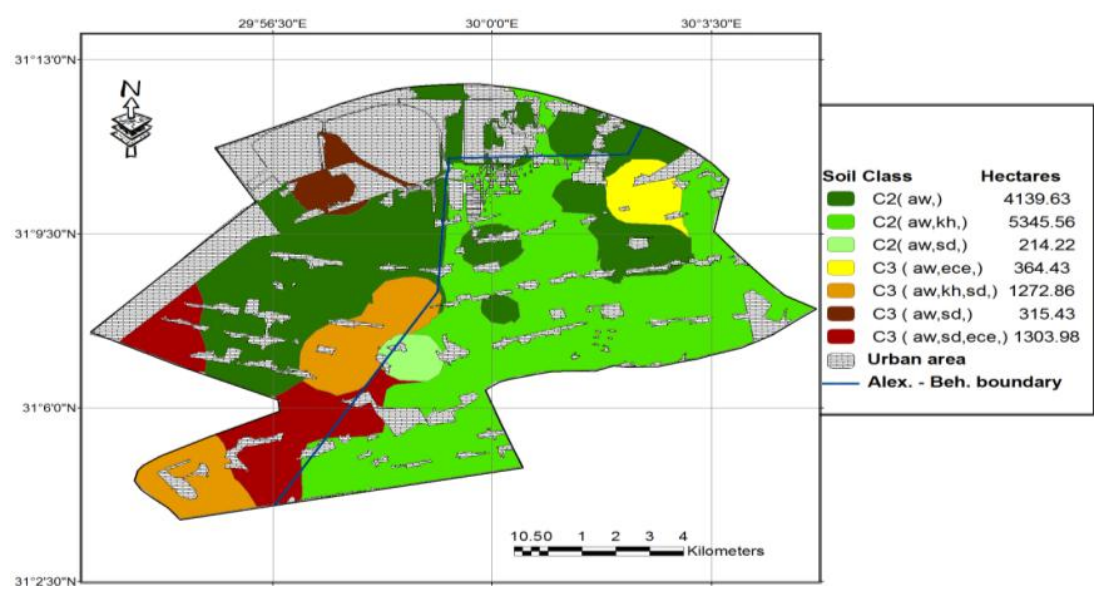

Map 3. Land capability classes of the study area.

\section{Materials and Methods}

\section{Materials}

Three satellite images

Three satellite images have been used in this study, Thematic Mapper (TM, 1984), Landsat Enhanced Thematic Mapper (ETM+7, 2005) and ETM+8 2013,

\section{Maps}

Topographic map of the study area produced by the Military Survey Authority in 1992 with scale 1:50000, and land capability map of the study area produced by Yehia et al. (2014).

\section{Methodology}

Georeferencing

Accurate per-pixel registration of multi-temporal remote sensing data is essential for change detection. The RMS error between any two dates should not exceed 0.5 pixels (Lunetta and Elvide, 1998).

Egypt. J. Soil Sci. 55, No. 3 (2015) 
In this study, geometric correction was carried out using ground control points from topographic maps to geocode the image of 2013 then, this image was used to register all the other images, the RMSE between different images was less that 0.5 pixel which is acceptable. Map to image registration is carried out for 2013 image, the image to image registration is performed for the remaining data sets.

\section{Normalized difference vegetation index (NDVI)}

The normalized difference vegetative index (NDVI,) is a calculation process, based on several spectral bands, of the photosynthetic output (amount of green stuff) in a pixel in a satellite image. It measures, in effect, the amount of green vegetation in an area. NDVI is calculated using the formula

$$
\mathrm{NDVI}=(\mathrm{NIR}-\mathrm{red}) /(\mathrm{NIR}+\mathrm{red}) .
$$

and produces output values in the range of -1.0 to 1.0 . There are various vegetation indices to enhance vegetation information in remote sensing imagery usually by ratioing a near-infrared (NIR) band to a red band. This takes advantage of the high vegetation reflectance in NIR spectral range such as TM band 4 and high pigment absorption of red light, such as TM band 3 (Jensen, 2000). Although nearly everyone working with the remote sensing of vegetation knows the Normalized Difference Index (NDVI), this study employed Soil Adjustment Vegetation Index (SAVI) to highlight vegetation features due to its advantage over NDVI when applied in an area with low plant cover such as the urban areas. SAVI can work in the area with plant cover as low as 15 percent, while NDVI can only work effectively in the area with plant cover above 30 percent (Ray, 1994). The SAVI is calculated using the following equation (Huete, 1988):

$$
\mathrm{SAVI}=(\mathrm{NIR}-\mathrm{Red})(1+1) /(\mathrm{NIR}+\mathrm{Red}+1)
$$

where 1 is a correction factor ranging from 0 for very high densities to 1 for very low densities. A value of 0.5 was used in this study to produce enhanced vegetation image as the study region has an intermediate vegetation density.

\section{Modified normalized difference water index (MNDWI)}

McFeeters (1996) proposed the normalized difference water Index (NDWI) to delineate open water features, which is expressed as follows:

$$
\text { NDWI }=(\text { Green }- \text { NIR }) /(\text { Green }+ \text { NIR })
$$

where Green is a green band such as TM2, and NIR is a near infrared band such as TM4. This index maximizes reflectance of water by using green light wavelengths and minimizes low reflectance of NIR by water features while taking advantage of the high reflectance of NIR by vegetation and soil features. Xu (2005) modified the NDWI by using a middle infrared (MIR) band such as TM5 to substitute the NIR band in the NDWI. The modified NDWI (MNDWI) is expressed as follows: 


$$
\text { MNDWI }=(\text { Green }- \text { MIR }) /(\text { Green }+ \text { MIR })
$$

The mean of TM5 is much greater than that of TM2. Therefore, if a MIR band is used instead of a NIR band, the built-up land should have negative values while keeping the water values positive. Accordingly, the enhanced water features will no longer have built-up land noise in a MNDWI image. This substitution has no impact on vegetation، as vegetation still has negative value when calculated using MNDWI Equation. The MNDWI was not calculated for 1984 image due to the lack of MIR band.

Normalized difference built-up index (NDBI)

The built-up land image was produced using the NDBI of Zha et al. (2003) with the following equation:

$$
\mathrm{NDBI}=(\mathrm{MIR}-\mathrm{NIR}) /(\mathrm{MIR}+\mathrm{NIR})
$$

The development of the index was based on the unique spectral response of built-up lands that have higher reflectance in MIR wavelength range than in NIR wavelength range. However, this is not always the case. Some studies showed that the reflectance for certain types of vegetation over the band pass of TM5 increased as leaf water content decreased (Cibula et al., 1992 and Gao, 1996). The drier vegetation can even have higher reflectance in MIR wavelength range than in NIR range (Gao, 1996), resulting in positive values in NDBI imagery for these plants. Furthermore, in some circumstances, water with high suspended matter concentration (SMC) can also reflect MIR stronger than NIR because the reflectance peak shifts to longer wavelength regions as the suspended matter increases. Therefore, the drier vegetation and water with high SMC will have positive NDBI values when computed using NDBI equation and present as noise in a NDBI image. Consequently, the contrast of the NDBI image is not so good as SAVI and MNDWI images, because many pixels of vegetation and water areas having positive NDBI values show medium gray tones and present as noise mixed with built-up features. These suggest that the urban built-up land features could not be extracted merely based on a NDBI image. This is why this study combines the NDBI with SAVI and MNDWI to extract urban built-up land features. This combination can remove the vegetation and water noise, and hence improve the extraction accuracy.

Index built-up index (IBI)

IBI is proposed for the rapid extraction of built up land features in satellite images. After producing SAVI, MNDWI, and NDBI images, a new image was created. A unique feature is that the mean value of built-up land is greater than those of vegetation and water in the NDBI band. Furthermore, the mean value of built-up land in the NDBI band exceeds its value in the SAVI band and the MNDWI band. According to these distinct features, the IBI can be created as follows:

Egypt. J. Soil Sci. 55, No. 3 (2015) 


$$
\mathrm{IBI}=[\mathrm{NDBI}-(\mathrm{SAVI}+\mathrm{MNDWI}) / 2]
$$

The index can enhance the built-up land feature easily because the subtraction of the SAVI band and the MNDWI band from the NDBI band will result in positive values for built-up land pixels only. The index takes advantage of the condition where the features with higher NDBI values but lower SAVI and MNDWI values will be enhanced. Obviously, the IBI is a normalized difference index and thus has such features as: 1) A ratio-based index, 2) values ranging from -1 to +1 and 3 ) enhanced information has positive values, while the suppressed background noise generally has zero to negative values. Dividing by two in the equation to avoid getting too small values of IBI.

\section{Overly of different indices layers}

To produce more accurate classified image ( land cover image ) for the study area we make overlay of different remotely sensed indices in geographic information system environment such as SAVI layer to identify the cultivated area, MNDWI to identify water bodies and flooded areas, and NDBI to characterize the urban areas. It is more accurate classified image and no time required to do it in GIS environment compared with unsupervised and supervised classification.

Directional distribution (standard deviational ellipse)

A common way of measuring the trend for a set of points or areas is to calculate the standard distance separately in the $\mathrm{x}$ - and $\mathrm{y}$-directions. These two measures define the axes of an ellipse encompassing the distribution of features. The ellipse is referred to as the standard deviational ellipse, since the method calculates the standard deviation of the $\mathrm{x}$-coordinates and $\mathrm{y}$-coordinates from the mean center to define the axes of the ellipse. The ellipse allows you to see if the distribution of features is elongated and hence has a particular orientation.

\section{Results and Discussions}

\section{Normalized difference vegetation index (NDVI)}

Results of NDVI calculation shows that medium cropping system represented $50 \%$ of the total area, followed by low density cropping system represented an area about $48 \%$ of the total area, and finally intensity cropping system represented $1 \%$ of the total area in year 1984 and in year 2013 the same trend was found (Maps 4, 5, and 6). But in year 2005 the results varied as the low density planted cover of an area about $17 \%$ of the total area, followed by the medium denise cropping system represented an area about $39 \%$, finally the high density cropping system covered about $44 \%$ of the study area. Knowing that the high denies cropping system is concentrated in the study area which is located at El Behira Governorate. These results are consistent with the fact that as in 2005 is considered the highest of reclamation process in the study area since the beginning of reclamation process. Then decline again happened as a result of encroachment on agricultural land and the January revolution and the non-existence of censorship on agricultural land protection. 
Modified normalized difference water index (MNDWI)

MNDWI is a helpful index to extract water bodies and wetlands separated from each other. In year 2005 the water bodies covered about 3125 fed. covering the harbor water, irrigation canals, drains, parts of Maruit Lake and fish farms. Wet land represented 837.43 fed, the rice was mainly cultivated land because this land grants to their rice cultivation. But in 2013, the wetland shrank to an area of about 295.8 fed. due to the shortage of irrigation water, as well as the laws criminalizing rice cultivation in the region, and the water bodies decreased to 2407.04 fed due to the drying of some parts of the Lake Maruit for use in expansions Urban (Maps 7 and 8 ). We can not make this application on the satellite image TM 1984 because it's a different date and there was no rice cultivation in this date.

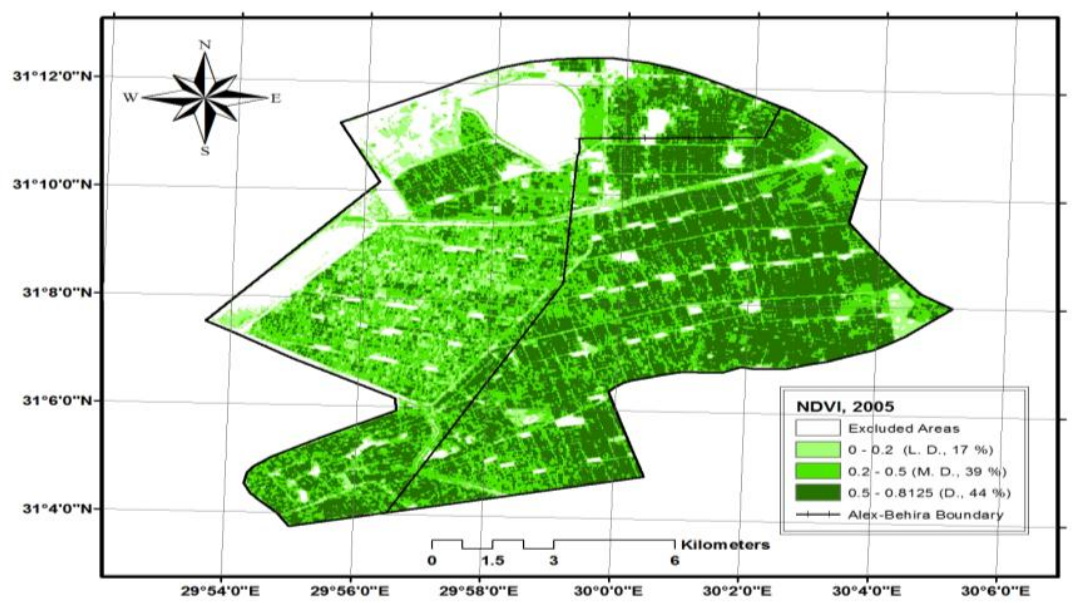

Map 4. NDVI for Abis area in 1984.

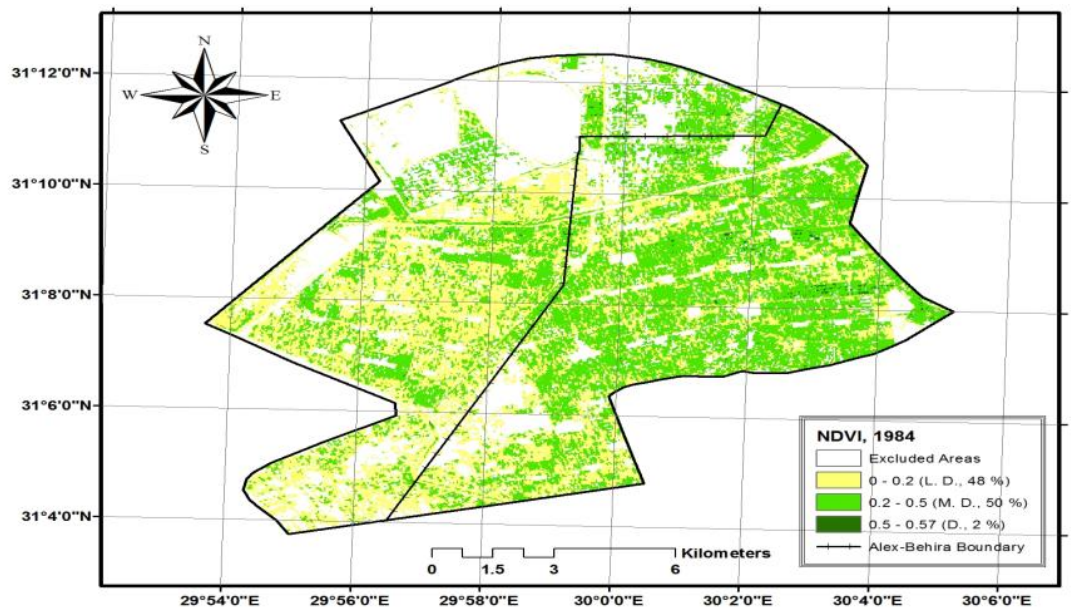

Map 5. NDVI for Abis area in 2005.

Egypt. J. Soil Sci. 55, No. 3 (2015) 


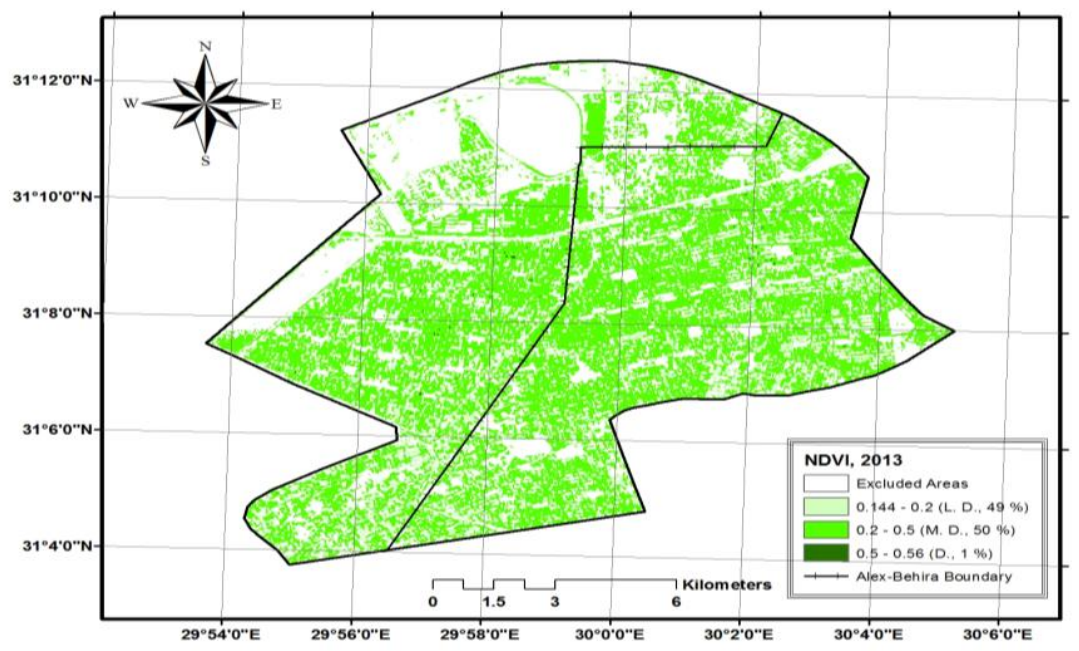

Map 6. NDVI for Abis area in 2013.

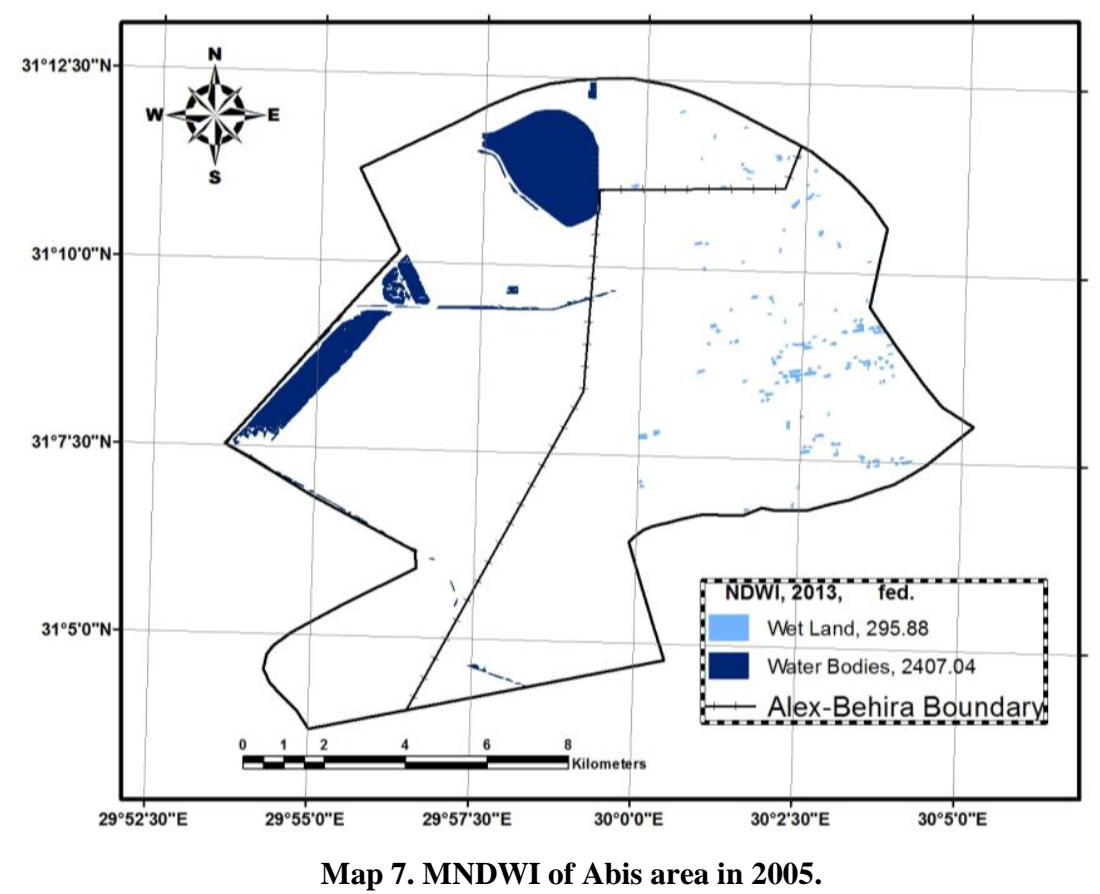

Egypt. J. Soil Sci. 55, No. 3 (2015) 


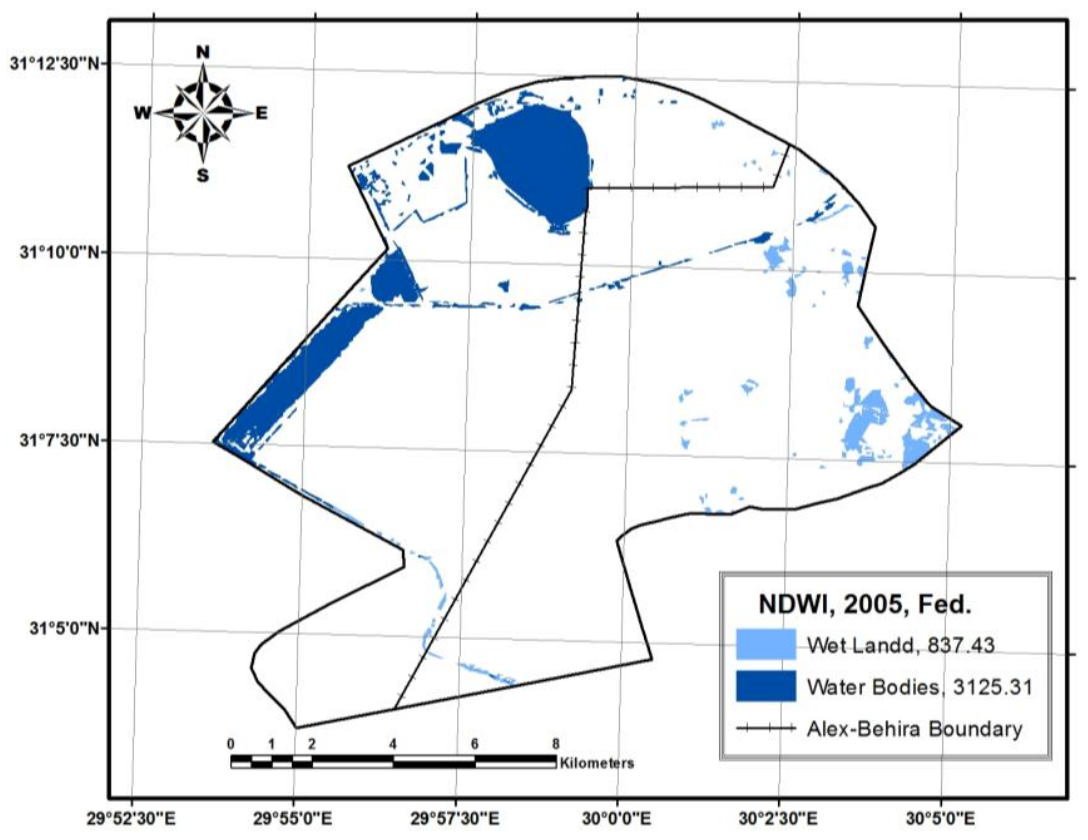

Map 8. MNDWI of Abis area in 2013.

Index built-up index (IBI)

NDBI was calculated as input parameters in the IBI equation to extract the bare soil and urban areas on the agricultural land in Abis area. After the calculation of the all remotely sensed indices (NDVI, SAVI, NDBI, and MNDWI) the IBI equation was used to extract both bare soil and urban areas in one step as one class. This is due to the similar interference between the bare soil and urban areas therefore it is difficult to delineate both by the IBI. The IBI results showed that the bare soil and area of buildings in TM acquired in 1984 was estimated as about 5613.51 fed. and decreased in ETM+7 2005 to 3117.64 fed. as a result of the beginning of reclamation process in the second part of the study area, which is concentrated in Alexandria Governorate. A comparison between the satellite image ETM+7 2005 and the satellite image ETM+8 2013, it was found that the bare soil and buildings had increased to nearly triple to reach in 2013 to 8264.12 fed. as a result of the terrible increased residential happened in this period as well as the ignorance of the people about the values of farmland and the absence of law and order in the period of revolution of $25^{\text {th }}$ January (Maps 9, 10, and 11 ). 


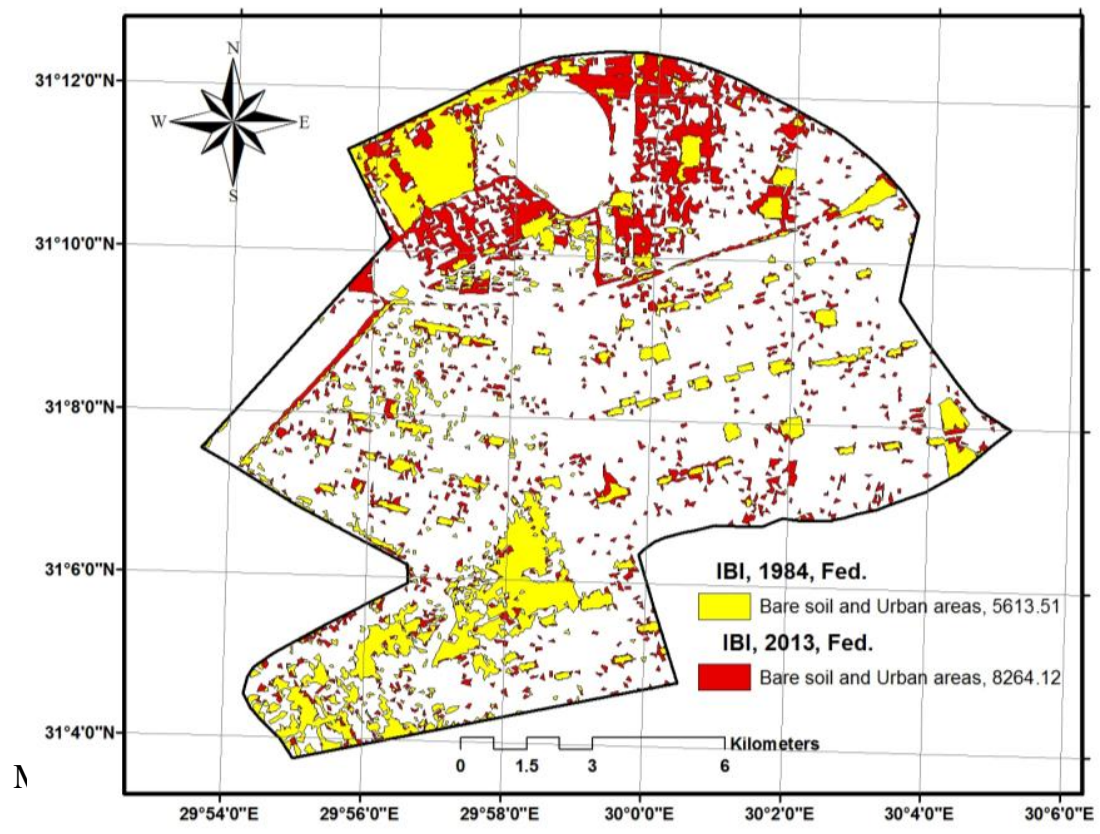

Map 9. Overlay of IBI in 1984 and 2013.

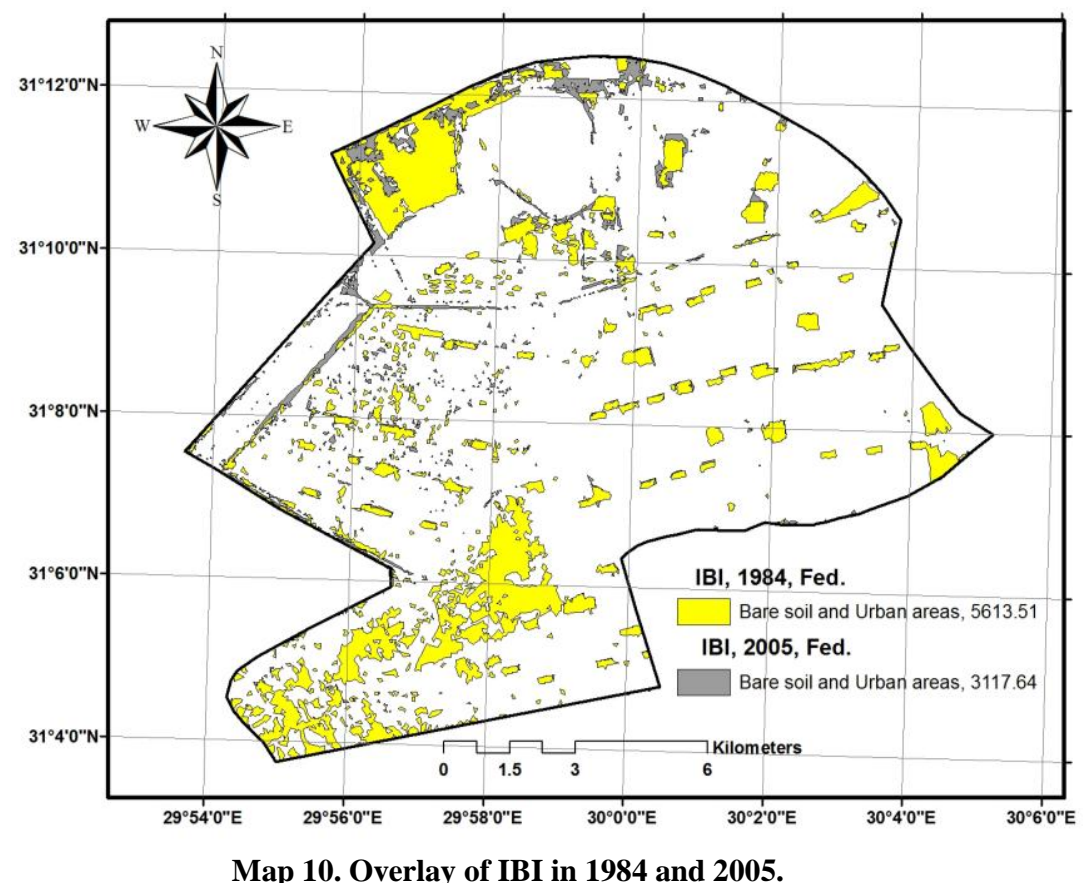

Egypt. J. Soil Sci. 55, No. 3 (2015) 


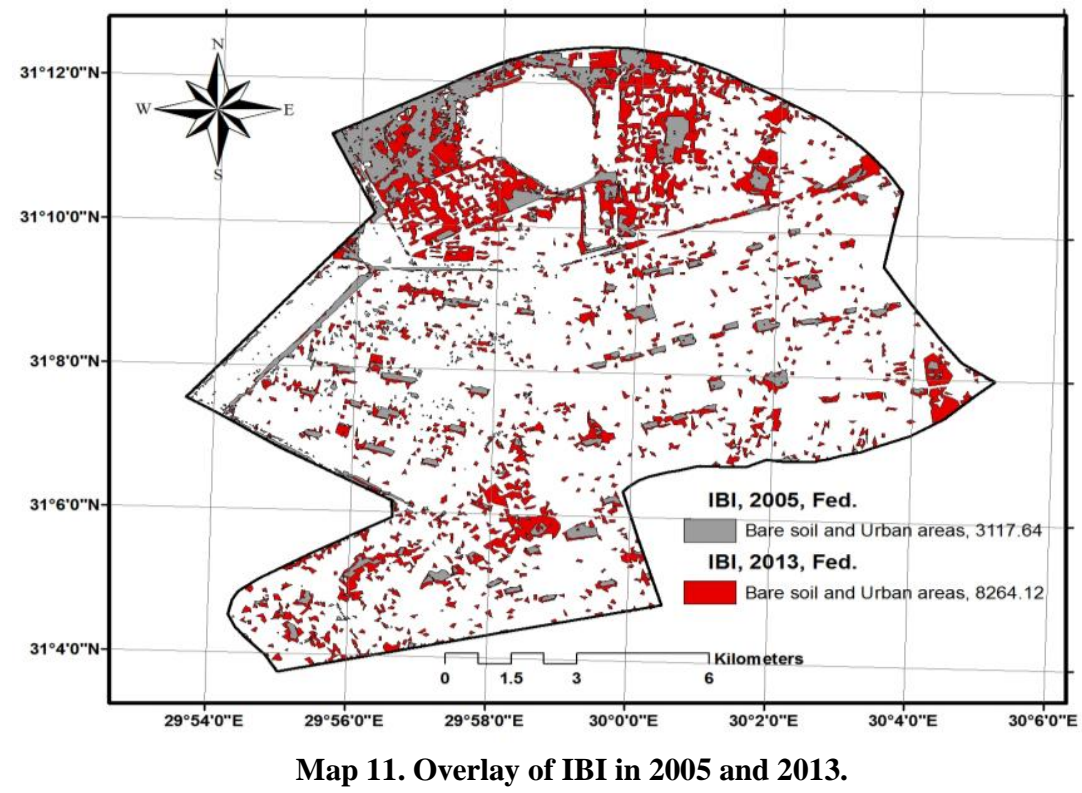

Bare soil and land evaluation

To study what has been lost from the fertile cultivated land of the study area, it has been overlay between both IBI maps and land capability classes map of the study area in GIS environment it was found that $\mathrm{C} 2$ class has lost about 5015 fed. of cultivated land which have had the ability to reach the $\mathrm{C} 1$ class by a little good management and good use. On the other hand, C3 class lost about 3249 fed. from its area as shown in Map (12) in 2013.

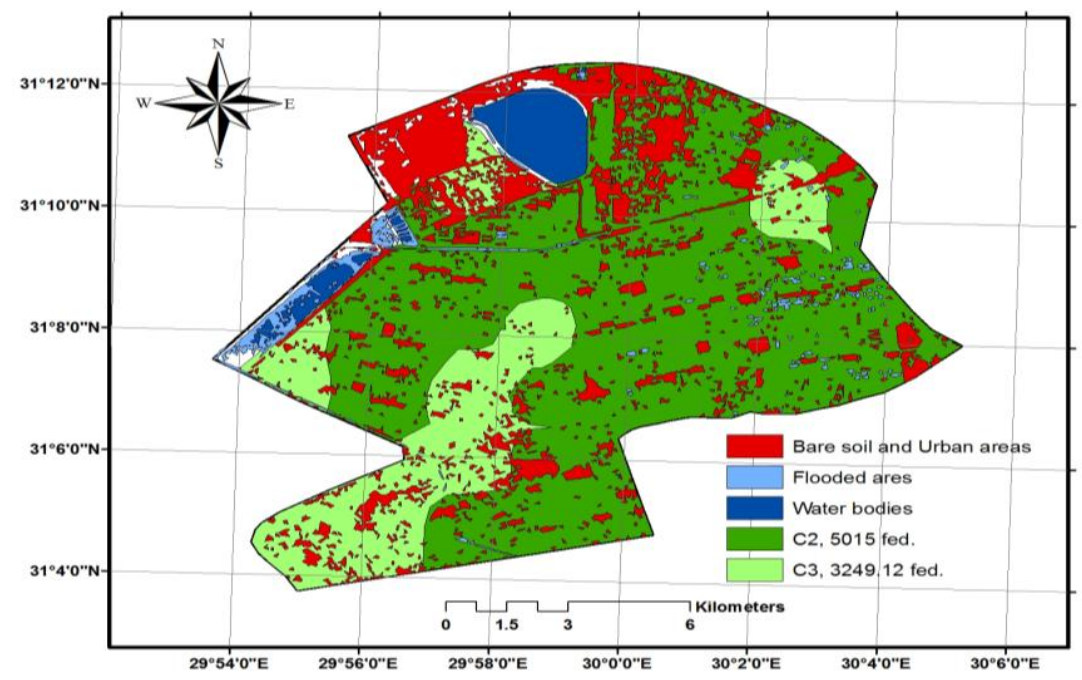

Map 12. Overlay of IBI on soil capability classes of the study area in 2013.

Egypt. J. Soil Sci. 55, No. 3 (2015) 


\section{Directional distribution (standard deviational ellipse)}

A simple and easy way to calculate and study the relationship and distribution of properties to each other in geographic information system environment based on spatial distribution and standard deviation of phenomena. It was found that there is a very strong relationship between the rate of urban encroachment, high level of ground water table and soil salinity distribution as shown in the Map13. Due to clogging of the drains in the study area and return of water back to the land, and it was found that the direction of propagation in the direction of urban cluster of Alexandria Governorate and this corresponds with reality.

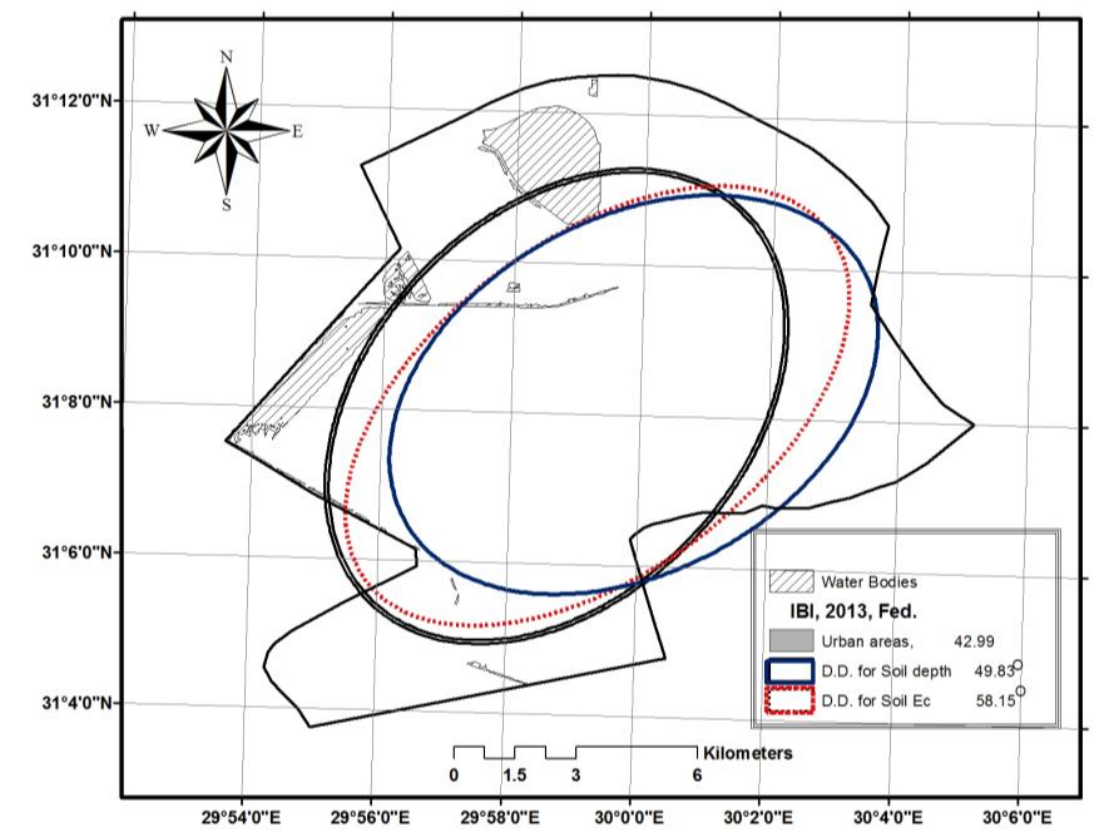

Map 13. Directional distribution of different phenomena in the study area.

\section{Remotely sensed indices overlay}

To produce a classified image more easily and accurate in no time using overlay technique in GIS environment, ArcGIS 10.1 was used and overlay process all remotely sensed indices such as NDVI, NDBI, MNDWI, and IBI to produce a land cover map included bare soil, urban areas, water bodies, flooded areas and cultivated area (Map 14).

\section{Accuracy assessment}

Table 1 shows that the validation of water index MNDWI and built up area IBI are carried out by random sampling method of the accuracy for the extracted water bodies, flooded areas, bare soil and urban areas features for 2013 image. For water index the total reference samples were 67 points, the user accuracy were 
closed to $98.48 \%$ and for the IBI the total reference samples were 95 points, the user accuracy were closed to $96.91 \%$. The results show that the remotely sensed indices show high accuracy assessment.

TABLE 1. Accuracy assessment.

\begin{tabular}{|l|c|c|c|c|c|}
\hline $\begin{array}{c}\text { Class } \\
\text { Name }\end{array}$ & $\begin{array}{c}\text { Reference } \\
\text { total }\end{array}$ & $\begin{array}{c}\text { Classified } \\
\text { total }\end{array}$ & $\begin{array}{c}\text { Number } \\
\text { correct }\end{array}$ & $\begin{array}{c}\text { Producers } \\
\text { Accuracy \% }\end{array}$ & $\begin{array}{c}\text { Users } \\
\text { Accuracy \% }\end{array}$ \\
\hline $\begin{array}{l}\text { Water Index } \\
\text { Bare soil and }\end{array}$ & 67 & 66 & 65 & 97.01 & 98.48 \\
Urban soil & 95 & 97 & 94 & 98.95 & 96.91 \\
\hline
\end{tabular}

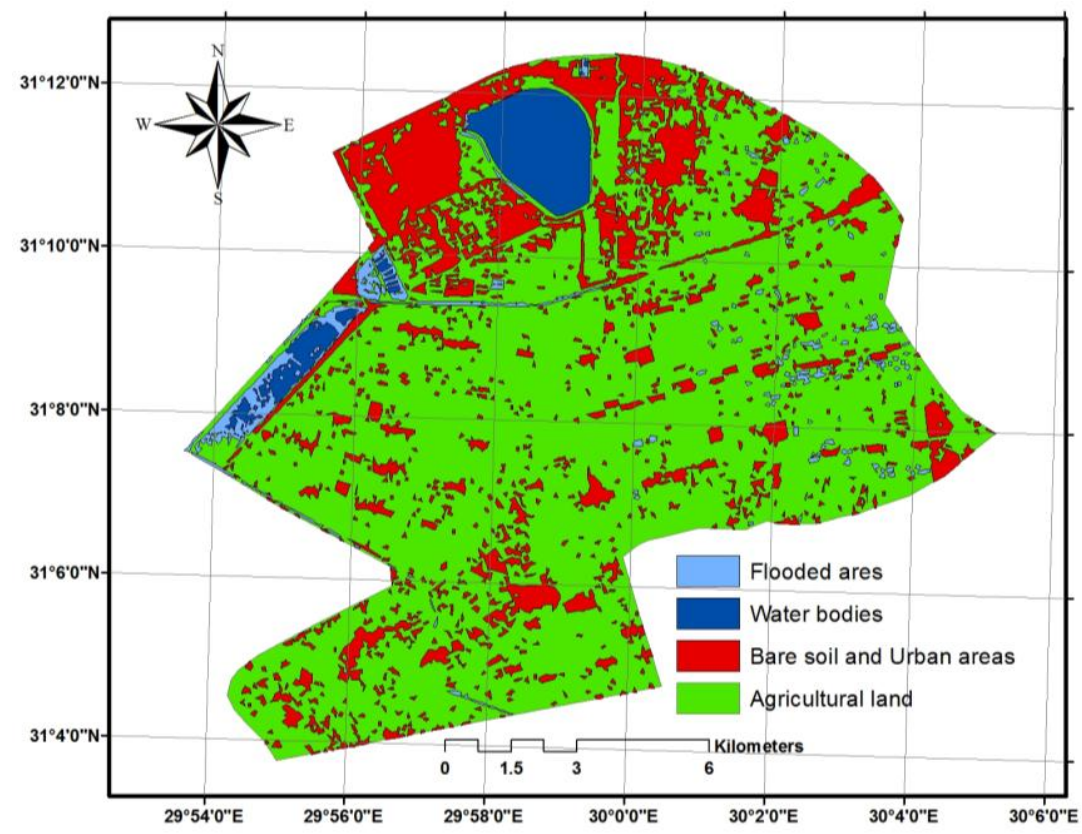

Map 14. Overlay of remotely indices for the study area.

\section{Conclusion}

IBI plays a key role to study bare soil and urban areas because it takes into account all other indices. The main causes of urbanization are the rapid population growth in addition to the internal. This problem needs to be seriously studied, through multi-dimensional fields including socioeconomic, in order to preserve the precious and limited agricultural land and increase food production. Directional distribution is a good method for mapping the distributional trend for a set of crimes might identify a relationship to particular physical features (a string of bars or restaurants, a particular boulevard, and so on). 


\section{References}

Afifi, A.A., Elsemary, M.A. and Wahab, M.A. (2013) Urban Sprawl of greater Cairo and its impact on the agricultural land using remote sensing and digital soil map. Journal of Applied Sciences Research, 9 (8), 5159-5167. J. Remote Sensing, 24 (3), $583-594$.

Amiri, Fazel and Tabatabaie. Tayebeh (2011) Using Remote Sensing data for Vegetation Cover Assessment in Semi-arid Rangeland of Center province of Iran. http://www.gdmc.nl/zlatanova/Gi4DM2010/gi4dm/Pdf/p18.pdf

Cibula, W.G. Zetka, E.F. and Rickman, D.L. (1992) Response of thematic bands to plant water stress. International Journal of Remote Sensing, 13 (10), 1869-1880.

Lunetta, R. S. and Elvidge, C.D. (1998) Remote Sensing Change Detection, Michigan: Ann Arbor Press

Gao, B.C. (1996) NDWI-A normalized difference water index for remote sensing of vegetation liquid water from space, Remote Sensing of Environment, 58 (3), 257-266.

Huete, A.R. (1988) A soil-adjusted vegetation index (SAVI), Remote Sensing of Environment, 25 (3), 295-309.

Hulme, M. and March, R. (1990) "Global Mean Monthly Humidity Surfaces for 193059, 1960-89 and Projected for 2020" UNEP/GEMS/GRID. Climatic Res. Unit, Univ. of East Anglia, Norwich, England.

Jensen, J.R. (2000) Remote Sensing of the Environment: An Earth Resource Perspective, Prentice Hall, Upper Saddle River، New Jersey, 544 p.

Lillesand, T.M. and Kiefer, R.W. (1994) Remote Sensing and Image Interpretation.. $4^{\text {th }}$ ed., New York, John Wiley and Sons.

McFeeters, S.K. (1996) The use of normalized difference water index (NDWI) in the delineation of open water features. International Journal of Remote Sensing, 17(7), $1425-1432$.

Rahman, A. Aggarwal, P.S. Netzband, M. and Fazal, S. (2011) Monitoring urban sprawl using remote sensing and GIS techniques of a fast growing urban centre, india. (IEEE) Journal of Selected topics in applied Earth Observations and Remote Sensing, 4, No.1 
Ray, T.W. (1994) Vegetation in remote sensing FAQs, Applications, ER Mapper, Ltd., Perth, unpaginated CD-ROM.

Thomas, I.L., Benning, V.M. and Ching, N.P. (1987) "Classification of Remotely Sensed Images". Bristol:Adam Hilger.

Xu, H. (2005) A study on information extraction of water body with the Modified normalized difference water index (MNDWI), Journal of Remote Sensing, 9 (5), $511-517$

Xu, H. (2008) A new index for delineating built-up land features in satellite imagery. International Journal of Remote Sensing. 29, No. (14), 20 July 4269 - 4276.

Yehia, H. A., El Ghonamey, Y.K. and El Shemy, A.S.A. (2014) Application of geographic information system using ales-arid module for land evaluation assessment of Abis Area, West Delta, Egypt. Minufiya J. Agric. Res. 39 No. 2 (2): 831 - 851. http://www.mujar.net.

Zha, Y., Gao, J. and Ni, S. (2003) Use of normalized difference built-up index in automatically mapping urban areas from TM imagery، International Journal

(Received: 5/11/2014; accepted:25/12/2014) 


$$
\begin{aligned}
& \text { استخدام دلائل تقتيات الاستشعار عن بعد لرصد وكثف التغيرات فى الرئ }
\end{aligned}
$$

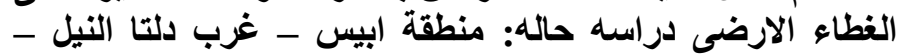

$$
\begin{aligned}
& \text { مصر }
\end{aligned}
$$

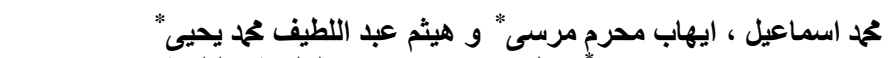

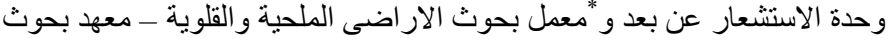

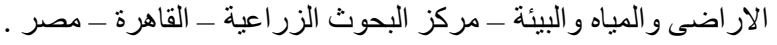

ان التغير ات الدقيقه و الدوريه فى استخدامات الار اضى هي عمليه غاية فى الأهمية

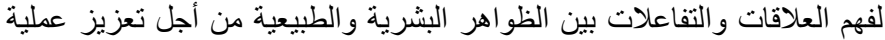

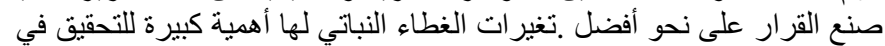

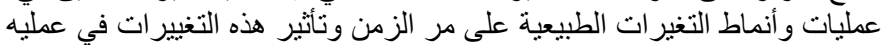

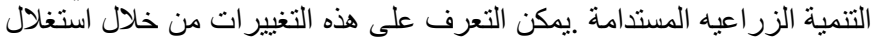

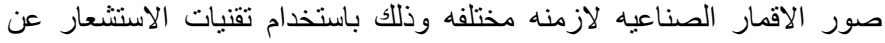

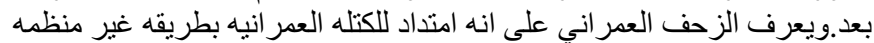

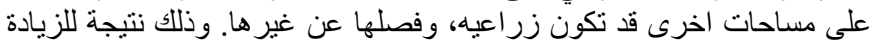

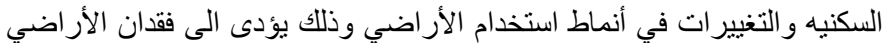

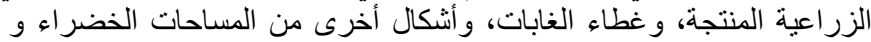

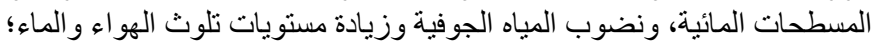

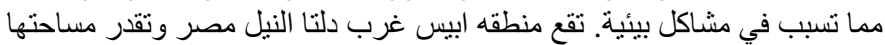

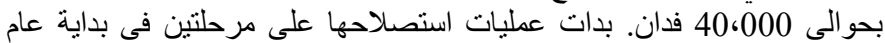
1960، وتقدر المرحلة الأولى بحوالي

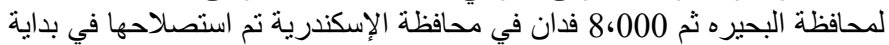

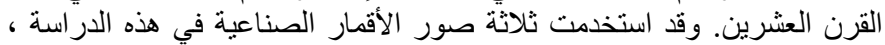

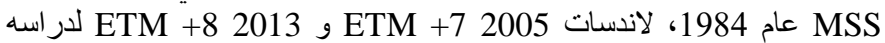

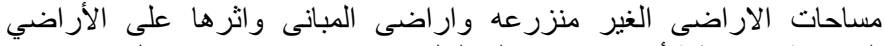

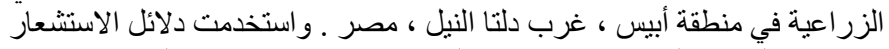

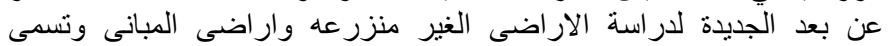

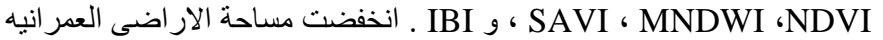

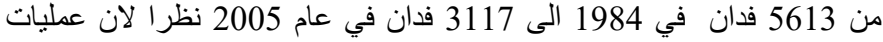

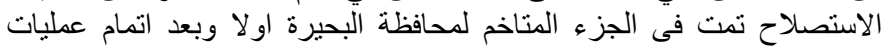

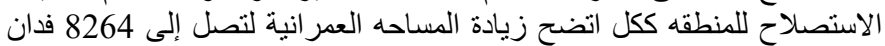

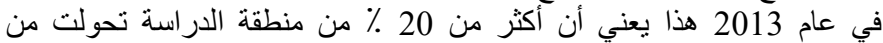

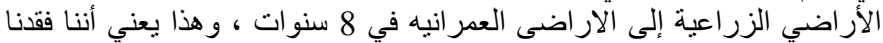

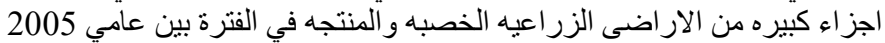

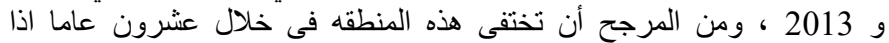
استمرت التعديات بنفس المعدل السابق. 